\title{
UNA POLÍTICA DE VIVIENDA INNOVADORA: LA EXPERIENCIA DE CATALUÑA
}

\author{
Dolors Clavell Nadal ${ }^{1}$ \\ Grup Parlamentari Iniciativa per Catalunya-Verds-Esquerra Unida i Alternativa \\ Parlamento de Cataluña.
}

Remisión Artículo: 2-9-2007

Palabras Clave: Política, vivienda, jóvenes, emancipación

Resumen: Las principales víctimas de la llamada crisis de inaccesibilidad a la vivienda que se sufre en España y Cataluña en los últimos años son las personas jóvenes en edad de emancipación, las personas mayores que viven de alquiler y no pueden afrontar los incrementos de renta, las familias monoparentales y los/las inmigrantes. Lo primero que creo interesante señalar es que son víctimas pero a mi juicio no deben ser revictimizadas con un discurso asistencial y plañidero. Al contrario, en especial las personas jóvenes deben convertirse en agentes activos en la lucha contra una situación que les perjudica, y por ello estas notas tienen como objetivo mostrar algunas claves para construir un discurso alternativo que permita un efectivo cambio en la política de vivienda tradicionalmente aplicada en nuestro país

\section{Emancipación y vivienda}

En materia de vivienda está demostrado que no hay disfunción entre la percepción subjetiva de la ciudadanía y la realidad objetiva de extrema dificultad en el acceso a la vivienda que sufre la población, que no afecta por igual a todas sus clases sociales y que se agrava hasta límites para todos imprevisibles hace unos años. La realidad de los datos nos muestra que, según el Consejo de la Juventud de España-Observatorio Juvenil de la Vivienda, el porcentaje de jóvenes emancipados en Cataluña es del $51,5 \%{ }^{2}$. Es un porcentaje mayor que en otros territorios de España y en los últimos años ha aumentado sensiblemente, pero la cifra de jóvenes por emancipar sigue siendo excesiva. Y también es importante conocer que un $80 \%$ de los emancipados en España lo son entre los 30 y 34 años y no antes. Así lo señalan recuentes estudios de la Unión Europea, en los que se indica que el porcentaje de jóvenes emancipados entre 18 y 24 años es del 8,6\% en España, frente al $48 \%$ en Grecia e Inglaterra, el $62 \%$ en Finlandia o el $40 \%$ en Francia ${ }^{3}$. Por lo tanto, poca emancipación y tardía sería la referencia básica que hay que tener en cuenta para situar la problemática de los jóvenes en España y Cataluña.

Es evidente que este fenómeno deriva de la precariedad laboral que afecta a la juventud y también de la dificultad -prácticamente imposibilidad- de acceso a la vivienda. El esfuerzo económico necesario para acceder a la propiedad de una vivienda libre -el alquiler y las viviendas protegidas siguen siendo escasas- no ha cesado de aumentar, hasta situarse en un nivel de endeudamiento equivalente al $69 \%$ del salario de una persona joven. Esto significa

\footnotetext{
${ }^{1}$ Persona de contacto Grup Parlamentari ICV-EUIA correo: grupicv-euia@parlament.cat

2 Informe núm. 17, cuarto trimestre 2006.

${ }^{3}$ First European Quality of Life Survey: Social dimensions of housing. European Foundation for the Improvement of Living and Working Conditions.
} 
que una persona joven sola ya no puede aspirar a pagar una vivienda, pues primero debe buscar pareja $u$ otras personas que la ayuden a pagarla. $\mathrm{Y}$, si finalmente consigue emanciparse con la fórmula más extendida -hipotecándose en la mayor parte del salario por 30, 40 o 50 años-, debemos reconocer que con ello se produce una hipoteca no sólo económica sino también vital, referida a muchas aspiraciones que son necesarias para el desarrollo de las personas en una sociedad que pretende alcanzar niveles de bienestar aceptables. Esta situación implica la renuncia a realizar actividades que nos han de interesar a todos: el estudio, un pequeño riesgo en un negocio o un trabajo, la cultura, la movilidad laboral, el ocio, la formación de una familia o la satisfacción de tantos otros estímulos que van mucho más allá de ahorrar todo el mes para pagar la hipoteca y poco más.

\section{La política de vivienda tradicional, hoy claramente insuficiente y desfasada}

A pesar del rotundo pronunciamiento contenido en el art. 47 de la Constitución, que proclama no sólo el derecho a una vivienda por parte de todos los ciudadanos sino la exigencia de su dignidad y el rechazo a la especulación inmobiliaria, la transición española no sirvió para incorporar la política de vivienda en la agenda política. Y, a pesar del fracaso de la política neoliberal de los diferentes gobiernos, aún hoy existe un número importante de personas que, incluso desde posiciones pretendidamente progresistas, se muestran reticentes a los mecanismos de intervención pública que permiten dar respuesta a las necesidades de vivienda de la población.

Los años 80 fueron desaprovechados para la equiparación con otros países europeos en la generalización de medidas dirigidas a atender una necesidad básica como la vivienda. De especialmente grave e imprudente debe ser calificada la primera liberalización del mercado de alquiler (1985) sin acompañarla de medidas en política de vivienda que mitigaran los previsibles efectos de exclusión sobre las personas y familias de menores recursos. En lugar de esto mantuvimos actuaciones públicas más dirigidas a garantizar una demanda estable al sector de la promoción y la construcción de viviendas (subvención tipos de interés y desgravaciones fiscales generalizadas) que a satisfacer a los ciudadanos necesitados de vivienda.

Con frecuencia se ha utilizado, como explicación de ese abandono, que el reconocimiento constitucional no se producía en el Título dedicado a los derechos fundamentales sino sólo entre los principios rectores de la política social y económica, lo cual no habría estimulado a nuestros gobernantes a afrontar la cuestión de la vivienda de forma seria. A mi juicio la explicación de la pasividad es más sencilla: en la transición, la percepción social y política no interiorizó que la vivienda se convertiría en un problema de primer orden si no se actuaba de forma más decidida desde los poderes públicos. De algún modo todos estaban acostumbrados a que el mercado iba dando respuesta a esas necesidades sin excesivas exigencias de política pública. Faltó previsión respecto a lo que ocurriría una vez España estuviera de lleno en el mercado mundial y en condiciones económicas muy distintas a las de la transición ${ }^{4}$.

El fracaso de las medidas de fomento a la promoción y construcción de viviendas protegidas y la subvención a los ciudadanos para la adquisición se ha hecho evidente en los últimos años (especialmente desde 1997), cuando el mercado inmobiliario se ha visto absolutamente condicionado por la presencia de una demanda de inversores y otros agentes con capacidad económica, que ha desplazado de forma injusta a las personas que únicamente precisan una

\footnotetext{
${ }^{4}$ En otro momento podrías analizar los intereses que pudieron existir y existen para fomentar la imprevisión y pasividad de los poderes públicos, relacionados con la tradicional influencia y cercanía al poder de determinados sectores económicos.
} 
vivienda para residir en ella de forma habitual ${ }^{5}$. Si hace no tanto tiempo era necesario acompañar esta apreciación de datos e informaciones estadísticas que la justificaran, hoy ya nadie puede discutir que resulta necesario cambiar una política de vivienda superada por las circunstancias del nuevo contexto económico en el que se desenvuelven España y Cataluña.

\section{Bases para una política de vivienda alternativa}

La presente reflexión entorno a la vivienda se enfoca desde la perspectiva de las personas jóvenes, y por ello lo primero que quisiera apuntar es que -en política de vivienda- no podemos caer en la interesada confusión de considerarlas un colectivo específico con necesidades especiales. Ser joven no es una clase social, es simplemente un estadio transitorio en nuestra vida, por el cual todos pasamos y superamos si hay suerte. En realidad, cuando hablamos de jóvenes y vivienda nos estamos refiriendo sencillamente a "demanda insolvente", pues el término joven por sí solo no incluye diferencias que son trascendentales y derivan de su concreta clase social, situación legal, red de apoyo, etc...

Por lo tanto, la política de vivienda que debe acometer un país para beneficiar a las personas jóvenes que desean emanciparse no debe centrarse en la fórmula simplista de la ayuda o la subvención para que puedan iniciar el pago de los plazos de un endeudamiento permanente durante toda su vida. Esa es la postura defendida desde una ideología conservadora que, sin cuestionar el resultado generado por un sistema de mercado injusto, se limita a asistir a las personas que no tienen su lugar en ese mercado y con ello perpetúa sus deficiencias.

Por el contrario, defendemos que los poderes públicos y también el sector inmobiliario deben implicarse en la resolución de los problemas de vivienda de la población y deben ofrecer viviendas a precio asequible a la ciudadanía, viviendas cuya obtención no obligue a un endeudamiento permanente y desproporcionado. No es razonable que el sector de la promoción inmobiliaria oferte sólo bienes dirigidos a los sectores económicamente más potentes de la sociedad, inversores incluidos, y desatienda sin rubor a las personas que sencillamente precisan un techo donde desarrollar un proyecto de vida.

Cabe matizar, sin embargo, que la situación grave de exclusión alcanzada en España y Cataluña conduce a no descartar hoy medidas asistenciales complementarias -y entre ellas las ayudas dirigidas a jóvenes-, pues resulta imposible convencer a la población de que, puesto que las soluciones ideadas son estructurales y tendrán efectos a largo plazo, mientras tanto deben mantenerse conformados y pacientes sin acceder a un bien de primera necesidad. Pero esas medidas han de considerarse un mero complemento de una política que esencialmente se dirija a tener una oferta de viviendas que la gente pueda comprar o alquilar. La consecución de este objetivo requiere la implicación de los sectores inmobiliario y financiero, pero también debe ser relevante una actuación legislativa que incorpore una mirada a los factores estructurales del problema, capaz de modificar la lógica de un mercado que entiende la vivienda única y exclusivamente desde la óptica de su valor de cambio, como inversión, desatendiendo su valor como espacio efectivamente utilizado para acoger un proyecto de vida.

Es ésta la base de la alternativa surgida y desarrollada a lo largo del proceso de reflexión que se ha producido entorno a una nueva legislación de vivienda en Cataluña, que se apoya en los siguientes planteamientos políticos y económicos:

\section{a) La propiedad de la vivienda debe cumplir su función social}

\footnotetext{
${ }^{5}$ No ha sido fácil, pero hoy en Cataluña ya no es posible negar que el precio de la vivienda en el mercado libre es siempre el máximo importe que se calcula puede afrontar la demanda. Los discursos que durante años han intentado convencernos de que el precio podría ser una simple suma de costes se reconocen ya como interesadamente desviados.
} 
Del mismo modo que en 1984 la Ley andaluza 8/1984, de 3 de julio, de reforma agraria supuso un paso trascendental en la concepción de la propiedad de la tierra ${ }^{6}$, entendemos que hoy no puede regularse la vivienda sin hacer mención a la función social que debe delimitar el contenido del derecho a su propiedad. Por lo tanto, el legislador ha de pronunciarse sobre ese aspecto $\mathrm{y}$, coherentemente, establecer en qué supuestos la comunidad considera que se incumple esa función social y qué tipo de penalización debe generar ese incumplimiento. Nuestro proceso de reflexión ha conducido a considerar que se incumple la función social de la propiedad en los siguientes casos, que deberán ser recogidos en la legislación de forma expresa:

- Incumplimiento injustificable del deber de conservación y rehabilitación, si ello supone un riesgo para la seguridad de las personas. Estamos ante una situación límite en que no puede aceptarse la pasividad en el cumplimiento del deber por parte de la propiedad de una vivienda.

- Desocupación permanente e injustificada de la vivienda. Este supuesto ha causado una enorme polémica en Cataluña, aunque parece razonable exigir que una vivienda cumpla con su función de ser techo de una persona o familia y no se convierta sólo en un bien de inversión. Sin negar la necesidad de medidas de fomento del alquiler, no puede hoy renunciarse a la penalización de desocupaciones injustificadas, pues así lo requiere el elevadísimo porcentaje de viviendas vacías existente en nuestro país. Criterios de sostenibilidad ambiental y social lo justifican plenamente.

- Sobreocupación injustificada de la vivienda. Las degradantes condiciones en que se producen situaciones de hacinamiento conducen a penalizar la actividad de explotación que puede existir en su trasfondo.

- No destinar a residencia habitual y permanente una vivienda protegida. Este supuesto sólo se refiere a las viviendas protegidas y está justificado en la exigencia de garantizar que éstas sirven a la finalidad de atender la real necesidad de techo de una persona o familia.

\section{b) La provisión de viviendas sociales, nuevo servicio público}

La realidad del mercado inmobiliario nos enseña que el problema de la inaccesibilidad a la vivienda no es algo coyuntural, sino que en un sistema de libre mercado en un mundo globalizado la oferta inmobiliaria del mercado libre se dirigirá siempre a los sectores con mayor capacidad de pago o de endeudamiento. Ante esa realidad, siempre será necesaria la intervención pública para respetar el derecho a la vivienda de todos.

Siendo así, el proceso de evolución de la política de vivienda debe acoger la idea de un nuevo servicio público -servicio de interés general en la terminología europea- dirigido a satisfacer las necesidades de vivienda a precio asequible ${ }^{7}$. Con esa nueva concepción, los promotores y constructores de viviendas sociales se convierten en agentes privados al servicio de una

\footnotetext{
${ }^{6}$ El Tribunal Constitucional, en STC 37/1987, declaró la constitucionalidad de la Ley andaluza de Reforma agraria, señalando claramente que el contenido esencial de la propiedad privada debe incluir la necesaria referencia a su función social.

${ }^{7}$ La dispersión terminológica existente en materia de vivienda es excesiva. Nuestra sugerencia es denominar "social" a toda vivienda con un precio limitado, pues precisamente es ese precio el que comporta que la vivienda pueda destinarse a políticas sociales diversas. Existirán diversas viviendas sociales o destinadas a políticas sociales, y entre ellas estarán -en Cataluña- las denominadas "con protección oficial", término que a su vez incluye diversas modalidades.
} 
política pública y sin perjuicio de la gestión directa que pueda acometer la propia Administración.

\section{c) Creación de un parque estable, integrado y diverso de viviendas sociales}

Las necesidades y posibilidades de vivienda social -precio limitado- deben ser objeto de planificación y programación, poniendo fin a las tradicionales actuaciones dispersas y puntuales que no conforman una política coherente y explicable. En esta línea, debe profundizarse en la relación entre suelo y vivienda, pues hoy resultaría totalmente desfasada e insatisfactoria una política de vivienda que no tuviera en consideración el proceso de transformación del suelo que hace o no posible la producción de viviendas a un precio limitado.

A mi juicio, debemos evolucionar en la obtención de viviendas protegidas y conseguir su producción también en la ciudad ya construida. Razones de integración espacial lo exigen. En el Proyecto de Ley del derecho a la vivienda de Cataluña se realiza un esfuerzo de concreción de esa posibilidad, que se instrumenta a través de la simple calificación urbanística en suelo urbano consolidado y que se basa en la posibilidad de destinar un suelo a edificación parcial o totalmente protegida, bajo el mismo principio que permite p.e. que un Plan establezca discrecionalmente una calificación de $\mathrm{PB}+4$ o $\mathrm{PB}+6$, o para un uso industrial, residencial o comercial.

La técnica de la calificación y de la reserva urbanística, junto con otros mecanismos ${ }^{8}$, ha de permitir la creación de un auténtico parque de viviendas sociales, viviendas con precio limitado. Y es conveniente establecer objetivos a largo plazo que obliguen a todas las Administraciones para lograr su consecución. La población ya no admite la pasividad en materia de vivienda, y hay que demostrar que existirá estabilidad en las actuaciones dirigidas a la obtención de un parque suficiente de viviendas a precio asequible.

Finalmente, la idea de conformar un parque suficiente e integrado de viviendas sociales ha de acompañarse inevitablemente de la fijación de un plazo extenso de protección en el caso de las viviendas protegidas. No puede seguir repitiéndose la experiencia de descalificación de esas viviendas en plazos relativamente cortos, pues ello contradice frontalmente la necesidad de un parque estable. Aquello que ha costado un enorme esfuerzo a la comunidad no puede pasar a formar parte del mercado libre y generar un plusvalor injustificado. En consecuencia, los plazos de protección de la vivienda protegida deben alcanzar toda su vida útil. Y, en la misma línea, no debe permitirse la descalificación de las viviendas a interés del propietario, pues ello supone contrariar el principio esencial de necesaria estabilidad del parque de vivienda protegida.

\section{d) Prestigiar la vivienda protegida: cambios en su régimen de adjudicación y transmisión}

La apreciada necesidad de incrementar el parque de vivienda protegida, y también de otros productos con precio limitado, exige poner fin a las prácticas fraudulentas y las operaciones con dinero opaco que caracterizan las adjudicaciones y transmisiones en ese parque. De ese modo, resulta exigible una apuesta por un régimen de adjudicación objetivo y transparente, y también un mayor control y transparencia en las posteriores transmisiones de las viviendas.

\footnotetext{
${ }^{8}$ Otras vías que pueden permitir la obtención de viviendas a un precio limitado son: creación de redes mediación en el mercado de alquiler (garantías al propietario a cambio de un precio inferior al de mercado); ayudas al alquiler a las personas o familias con escasos ingresos; aplicación de la técnica del derecho de tanteo y retracto sobre transmisiones en el mercado libre y su conversión en viviendas de precio limitado; actuaciones de conservación y rehabilitación que den lugar a viviendas asequibles.
} 
Ello supone un reto ingente para la Administración pública, que debe mejorar en agilidad y capacidad de respuesta en los procesos de adjudicación y ejercicio de derechos de tanteo y retracto, pero debe ser afrontado para prestigiar un producto imprescindible para la política pública de vivienda.

\section{e) Calidad de todas las viviendas, libres y protegidas, nuevas y existentes}

Pasar de una política meramente economicista a otra que potencie el valor de uso de las viviendas no puede desconocer aspectos como los siguientes: establecimiento de mayores exigencias de calidad en las nuevas viviendas; inclusión de parámetros de sostenibilidad y eficiencia ambiental; superación de los modelos basados en la concepción jerárquica y la discriminación de género; atención a la diversidad de formas de vivir la vivienda, que hoy superan en mucho al modelo de familia tradicional. En este sentido, sería interesante recuperar la idea de que la superficie de las viviendas debe determinarse en función de las prestaciones que se pretenden cubrir en ella. Y es el momento de apostar por la adaptabilidad del espacio a las necesidades cambiantes de los usuarios, como una forma de prolongar su confort y el valor de uso de su vivienda. Y debemos pensar también en edificios y viviendas accesibles y utilizables por personas con dificultades de movilidad -temporales o permanentes, universalizando así el uso de las viviendas y mejorando las prestaciones para todos.

Parte de estas innovaciones deberán vehicularse a través de una política de vivienda pública más arriesgada y experimental, y otras habrán de dar lugar a nuevas normas de habitabilidad exigibles en todo tipo de viviendas.

Además, es hora de poner en marcha operaciones de experimentación en las formas de tenencia de la vivienda. Hoy existen colectivos, especialmente de personas jóvenes, dispuestos a arriesgarse en alternativas innovadoras en cuanto a formas de vivir, en barrios sostenibles, con flexibilidad tipológica, formando cooperativas de uso, etc...

También las viviendas ya existentes merecen previsiones acerca de su calidad, con lo cual deben generalizarse las inspecciones técnicas y los requerimientos para su mantenimiento. En zonas degradadas, los mecanismos de conservación y rehabilitación deben ser más complejos para dar respuesta a las muy diversas realidades existentes, y de ellos ha de poder obtenerse también vivienda protegida. Los ocupantes de las viviendas no deben ser los perjudicados en operaciones de rehabilitación.

\section{f) Protección de las personas y colectivos más débiles en el mercado}

La acreditación de que el mercado libre genera exclusión de los sectores más desfavorecidos nos conduce a reivindicar un tratamiento legal favorable a esas personas y colectivos. En concreto, nos referimos a:

- Consumidores: La realidad del sector inmobiliario exige una regulación de la actividad de intermediación inmobiliaria que proteja al más débil, tanto en la publicidad como en la oferta y la transmisión o arrendamiento de la vivienda. No son tolerables las situaciones de abuso que vienen produciéndose en un mercado absolutamente desregularizado.

- Víctimas de situaciones anómalas, expresión que utilizamos para describir los fenómenos de desocupación, sobreocupación e infraviviendas. En estos casos deben ponerse en marcha mecanismos de penalización de la anomalía, que acompañen a las técnicas dirigidas a incentivar el fin de la misma. 
- Víctimas de acoso inmobiliario. En especial en grandes ciudades ha surgido de forma especialmente virulenta el fenómeno del acoso, practicado por compañías con intereses especulativos dispuestas a realizar todo tipo de actuaciones inaceptables en perjuicio de los ocupantes legales de las viviendas y buscando su expulsión. Hoy es exigible que la normativa penalice duramente estas prácticas y proteja de forma especial a la parte más débil. El acoso debe ser considerado discriminación y a esos efectos aplicarle la inversión en la carga de la prueba que las directivas europeas establecen.

- Personas y colectivos vulnerables. En la adjudicación de viviendas sociales debe existir un cupo especial que permita dar cabida a la situación de personas con problemas de exclusión social, que pueden estar originados por muy diversas causas.

\section{g) Asunción del problema de la vivienda desde la política económica}

Defender la integralidad de una política de vivienda no puede obviar las decisiones de la política económica. El proceso de reflexión entorno al Proyecto de Ley del derecho a la vivienda en Cataluña nos ha permitido tomar conciencia de que, más allá del esfuerzo normativo contenido en el Proyecto, existe un campo sobre el cual no tenemos competencias sustanciales y que es trascendental para dar un vuelco a la realidad actual en materia de vivienda. Se trata del marco económico y especialmente fiscal e hipotecario, desde el cual podrían afrontarse medidas de efectos mucho más inmediatos que cualquiera de las vías y mecanismos de intervención establecidos desde la estricta competencia sectorial de vivienda.

Y la política económica está aún muy lejos de elaborar un discurso alternativo a la tradicional pasividad ante la evolución del mercado inmobiliario ${ }^{9}$. Llamamos pues la atención sobre este vacío, que puede significar un retraso en la adopción de criterios eficientes para la resolución de las carencias del país en materia de vivienda. Su vinculación con la economía es innegable y difícilmente avanzaremos en políticas eficaces si esa vinculación no se integra en el discurso económico general.

\footnotetext{
${ }^{9}$ Nótese que hoy existe alarma por el incremento de los tipos de interés de los créditos hipotecarios, pero cuando éstos se redujeron notablemente no se hizo nada para evitar que esa reducción quedara automáticamente absorbida por los precios de la vivienda en el mercado libre. La reducción de los tipos de interés benefició pues a los vendedores de vivienda y el incremento perjudica ahora a los ciudadanos adquirentes, con lo cual se produce una situación radicalmente injusta y contraria al interés general de la población, con el agravante de haber sido previsible y anunciada sin haber dado lugar a la adopción de decisiones de política económica mitigadoras de esos efectos.
} 


\section{La opción legislativa de Cataluña: Estatut y Ley del derecho a la vivienda de Cataluña}

Las novedades legislativas ${ }^{10}$ más recientes en Cataluña se encuentran en el texto de su nuevo Estatut -ya aprobado- y en el Proyecto de Ley del derecho a la vivienda, en trámite parlamentario cuando se escriben estas líneas. De momento el contenido de ambos textos ha pasado sorprendentemente desapercibido en el debate público, más entregado a polémicas superficiales que a la discusión de problemas de fondo con trascendencia ciudadana. Por ello interesa destacar que en estos últimos años ha habido y está habiendo una reflexión sobre temas estructurales de enorme interés, que algún día deberá aflorar. Entre estos temas se encuentra sin lugar a dudas la vivienda y qué mecanismos debe tener la comunidad para intervenir de forma eficaz en la provisión de este bien esencial.

\section{a) Estatut de Autonomía de 2006}

El muy discutido pero poco conocido texto del nuevo Estatut de Cataluña incluye una innovación trascendental en materia de vivienda, al obligar a los poderes públicos del país a tener una política propia. En el futuro ya no podrá ocurrir lo que estuvo sucediendo durante la época de 23 años de poder conservador, cuando Cataluña únicamente gestionaba los recursos recibidos de los Planes estatales de vivienda, sin haber conformado nunca una auténtica política ni haber destinado presupuesto propio a esa finalidad.

El Estatut regula el acceso a una vivienda digna como un derecho para todas las personas sin recursos suficientes. Las condiciones las determinará la ley específica, obviamente, pero la norma suprema obliga a dar respuesta a este derecho, por otra parte tutelado por el Consejo de garantías estatutarias y el Síndic de Greuges $^{11}$ (arts. 38.1 i 78) y con la protección de los Tribunales en caso de vulneración (art. 38.2).

Además, en el art. 40.4 se realiza una explícita referencia a la obligación de los poderes públicos de promover políticas públicas que favorezcan la emancipación de las personas jóvenes, facilitándoles entre otros el acceso a la vivienda "para que puedan desarrollar su proyecto de vida y participar en igualdad de derechos y deberes en la vida social y cultural".

También el art. 47 señala que los poderes públicos han de facilitar el acceso a la vivienda mediante la generación de suelo y la promoción de vivienda pública y protegida, con una atención especial a jóvenes y colectivos más necesitados. Finalmente, el art. 137 nos relaciona el alcance de la competencia exclusiva en materia de vivienda que corresponde a la Generalitat.

Estamos pues obligados a tener una política propia de vivienda en Cataluña. Obviamente, ésta será distinta en función del gobierno en el poder, que pondrá más énfasis en unas u otras cuestiones según su posicionamiento ideológico, pero debe existir ya siempre una política. No es nada irrelevante este reconocimiento en la ley de leyes del país.

\footnotetext{
${ }^{10}$ Si no nos centráramos en las medidas estrictamente legislativas, sería el Pacto Nacional para la Vivienda, elaborado por el Gobierno de Cataluña, la apuesta más trascendental a comentar. El Pacto compromete más de más de 800.000 actuaciones y más de $8.000 \mathrm{M} €$ para política de vivienda, en un esfuerzo excepcional e inaudito. Al realizar este trabajo el Pacto se encuentra pendiente de aprobación, después de un proceso de gestación muy complejo que ha generado rechazo en una parte del sector de la promoción inmobiliaria. Habiéndose iniciado ya la temida crisis inmobiliaria, no parece una posición acertada mantenerse ajeno a las propuestas políticas y el importante compromiso presupuestario que surgen del Pacto.

${ }^{11}$ Expresión con la que se denomina al Defensor del Pueblo en Cataluña.
} 


\section{b) El Proyecto de Ley del derecho a la vivienda}

El texto que hoy se encuentra en trámite parlamentario ha sufrido un proceso de gestación realmente interesante y también complejo y duro, pues al inicio de la reflexión sobre qué debía contener hoy una ley de vivienda partíamos de un vacío total de antecedentes o propuestas de enfoque distinto al tradicional, como hemos ya señalado totalmente superado por la realidad del país. Interesa señalar que Cataluña es la primera Comunidad Autónoma que se ha atrevido a plantear una regulación integral e innovadora de la vivienda, con lo cual lo ha hecho sin referencias previas que facilitaran ese trabajo ${ }^{12}$.

Transformar la insatisfactoria realidad de partida ha sido uno de los retos de estos años, con la celebración de seminarios de debate y foros de reflexión que permitieran ir asentando ideas y posiciones constructivas. Creemos que progresivamente irá corrigiéndose el déficit de ideas apreciado, en especial porque muchas personas jóvenes muestran hoy su interés por la política de vivienda. Una mirada distanciada nos permite aventurar que el futuro ha de ser mucho más rico que la realidad de hoy, y que las ideas y el deseo de innovación prevalecerá sobre la pasividad que en este tema ha caracterizado a nuestro país durante demasiados años.

El Proyecto de Ley contiene todos y cada uno de los aspectos analizados en el apartado 3 del presente trabajo, a excepción de las referencias a decisiones de política económica y fiscal que, según ya se señala en su subapartado g), son competencia del Estado. Es interesante destacar que el texto ha sufrido un proceso de discusión agotador, pues desde principios de 2005 en que tuvimos unos primeros borradores ha existido la expresa voluntad de reflexionar acerca de todo su contenido y de mejorar y corregir sin límites. Esto ha conformado $-y$ sigue conformando hoy, en la discusión parlamentaria- un texto sin duda alguna muy participado pero también hijo de muchas y muy diversas aportaciones, lo cual a veces nos genera dudas acerca de la capacidad de su asimilación, tanto social como por parte de la maquinaria administrativa que deberá aplicar la nueva ley. Ante esas eternas e inevitables dudas, hemos decidido que lo importante es aprobar la ley y estar dispuestos a evaluar su corrección posteriormente, pues deberíamos normalizar el hecho de que cualquier aportación innovadora sufra precisamente las consecuencias de ser innovación aún no contrastada. Por lo tanto, nuestro deseo es mantener el estímulo intelectual y la reflexión de forma permanente, abiertos a las mejoras que en el futuro deriven de la aplicación del texto.

\footnotetext{
12 Después de Cataluña, el País Vasco es la Comunidad que con más fuerza e interés está elaborando un texto también innovador: Anteproyecto Ley de garantía del derecho ciudadano a una vivienda digna.
} 
Architecture, City, and Environment

Arquitectura, Ciudad y Entorno 